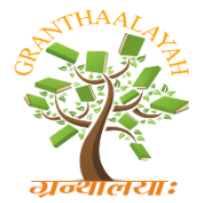

\author{
INTERNATIONAL JOURNAL OF RESEARCH - \\ GRANTHAALAYAH \\ A knowledge Repository
}

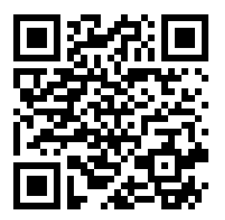

Science

\title{
COMPARISON OF PLOUGHSHARE BOLTS HARDNESS AND COEFFICIENT OF FRICTION PROPERTIES
}

\author{
Ferhat KÜP ${ }^{* 1}$ \\ ${ }^{*}$ Harran University, Faculty of Agriculture, Department of Agricultural Machineries and \\ Technologies Engineering, Şanlıurfa/Turkey
}

\begin{abstract}
Parts working in soil are exposed to effects of different abrasive particules in soil. Hardness of the particules that is mostly higher than tools' causes the tool to be worn or broken. The tools are made in detachable form in order to prevent to be broken. The form is mostly made with bolts and nuts. One of agricultural tools working in soil, Ploughshare is joined to plough beam with bolts. The galvanised bolts are manufactured in form of countersunk head and DIN 604 standard. In our study, hardness (HB) and friction coefficient $(\mu)$ of six different plough bolts are examined. The average values of friction coefficient are determined as $0.20,0.24,0.16,0.12,0.15,0.18$ and Hardness' 121, 137, 105, 100, 101, 111 respectively.
\end{abstract}

Keywords: Ploughshare Bolts; Hardness; Coefficient of Friction.

Cite This Article: Ferhat KÜP. (2019). "COMPARISON OF PLOUGHSHARE BOLTS HARDNESS AND COEFFICIENT OF FRICTION PROPERTIES." International Journal of Research - Granthaalayah, 7(5), 1-9. https://doi.org/10.29121/granthaalayah.v7.i5.2019.817.

\section{Introduction}

From the earliest times, human beings have tried to make things useful for themselves by using what they find around. While this was a process, it was done with simpler methods in the beginning, and verities and advanced methods are started to be applied over time. This development process is also observed in the gathering of the same or different kinds of equipment that we have seen in our surroundings. For example, many different methods such as casting, welding, screwing, riveting etc. have started to be applied in the course of time when the joining of the materials is done by using leather or wood branches. Today, there are many different methods of joining together the same or different kinds of materials. A number of different criteria are applied in the selection of these methods. We can refer to some of these criteria as melting point, corrosion resistance, physical and mechanical properties, aesthetics, working conditions of the material. It has been reported that material properties are related to abrasiveness, and these of properties have some effects on it, and these properties are material composition, yield stress, elastic modulus, hardness [1]. In addition, the joining of the materials is done in the form of dismountable or non-removable connections. In the design of any machine, which parts are 
detachable, which parts can not be removed, various criteria are taken into consideration. For example, any load on the part being used is fixed if no tension is present. However, if the part is subjected to variable loads and stresses, the deformation is done in a detachable state since the risk is high. Likewise, critical parts (expenses, difficult to produce, and affecting the entire system, etc.) are made detachable. Particular attention should therefore be paid to the manufacture of parts which are subject to such continuous wear. Otherwise, the part will break down in a much shorter period of time than desired [2].

Agricultural machinery and equipments are also produced by considering the above mentioned rules. Particularly in the agricultural mechanics, the parts that work with the soil contact with the abrasive particles in the soil wear off quickly and deform. In the article on the determination of wear value, weight loss was observed and compared in different field tests using certain hours in field tests [3]. In addition, these parts are sometimes exposed to extreme difficulty. For these reasons, such parts are made removable. The method used for this is a bolted connection. There are also criteria to increase resistance to wear of these parts and to make the breakage resistance of the bolted connection used lower than the original material. In the article [4], the discotic disc root obtained from the virtuous 5040 non-alloyed refinement steel was of heat treated at different annealing temperatures at $9500 \mathrm{C}$ curing temperature and measured the wear values in the field. As a result, he stated that there was no major change in wear. The increase in wear does not only cause a negative in terms of parts, but it also causes energy consumption. [5] examined the effect of differentiated cultivator endmills on the pulling force of the abrasion and tractor feed speed during operation. As a result of the study, it was stated that the increase in the speed of the tractor advancement increased the pulling force and that was difficult to get into the soil with the increase of the wear at the ends, thus causing the working depth not to be smooth.

Plow ends are a part of the soil. Various studies have been carried out for this part to function for the longest time without wear. [6] shown that the plow tip anchor was more resistance to superficial wear when it is covered with ZEDALLOY VB surface leveling electrode. [7] investigated the wear rates of plow-tip anchors with various carbon contents and different alloy characteristics using a rotating wheel-type abrasion tester in the laboratory environment. As a result, hardness seems to reduce wear but there is no correlation between them. The plow ends are connected to the feet by bolted connections. For this reason, the bolt breaks when compared to any compulsive force of the plow end, preventing the plow end pin and other systems from being damaged. There are some considerations noted in the cable connections. For example, the stresses that come to these auspices, the material of the bolt, the hardness, the yield and tensile stresses of the bolt, we can say among. [8] stated that although the static tensile values of bolts are important in the master's thesis, bolts operate at dynamic variable stresses. For this reason he stated that the behaviors they showed in dynamic changing stresses should be examined. [9] In his master's thesis, MILA 46100 investigated the behavior of the high alloy armor steel plate in tensile testing by combining the plates with bolt-nut connections at different metric gauges. As a result, it has been stated that M12 "samples carry more load than M10" samples without allowing for plastic deformation. [10] pointed out that the resolutions that occur during operation in screwed connections in their articles cause various problems. Especially in bolt connections in cars, they have proposed a new methodology to prevent this. 
Plow tip boring bolts are countersunk head machined with a galvanized finishing according to DIN 604. It has a tensile stress of $8 * 8$, i.e. tensile stress of $800 \mathrm{~N} / \mathrm{mm} 2$ and yield stress of $640 \mathrm{~N} /$ $\mathrm{mm} 2$. In this study, friction coefficients and hardness measurements of 6 different bolts were compared. It is expected that the results of this study will be important as well as the work to be done at the same time, since the physical and mechanical properties of plow-tip drill bolts have both direct and indirect impacts on both endmills and soil operations as well as on the tractor.

\section{Materials and Methods}

\subsection{Ploughshare Bolts}

Ploughshare bolts are countersinks manufactured in galvanized coatings according to DIN 604 standard. The general standards for the measurements are given in Figure 1.

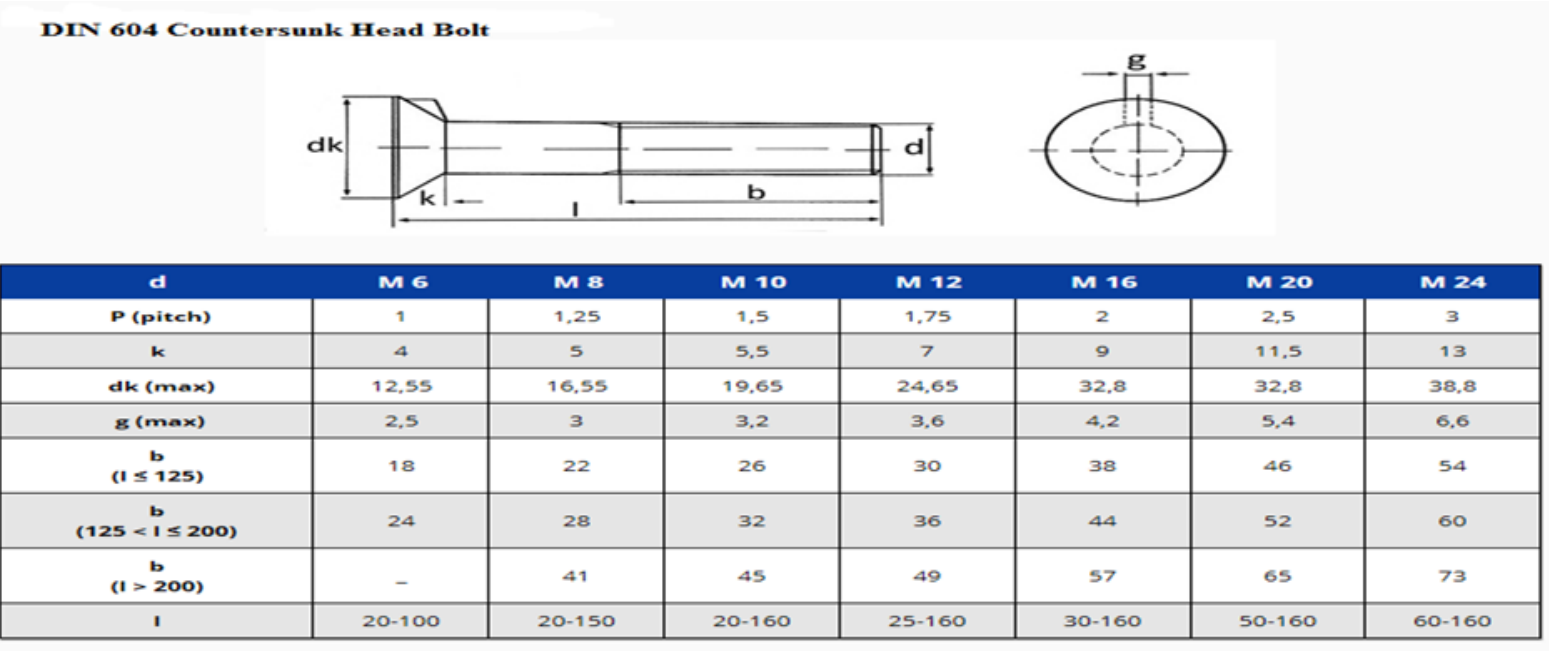

Figure 1: DIN 604 standards

Six bolt-nut connections from different manufacturers were used in this study. Initially, the specimen was taken from these bolts at a certain size and processing start. The bolt samples are shown in Figure 2.

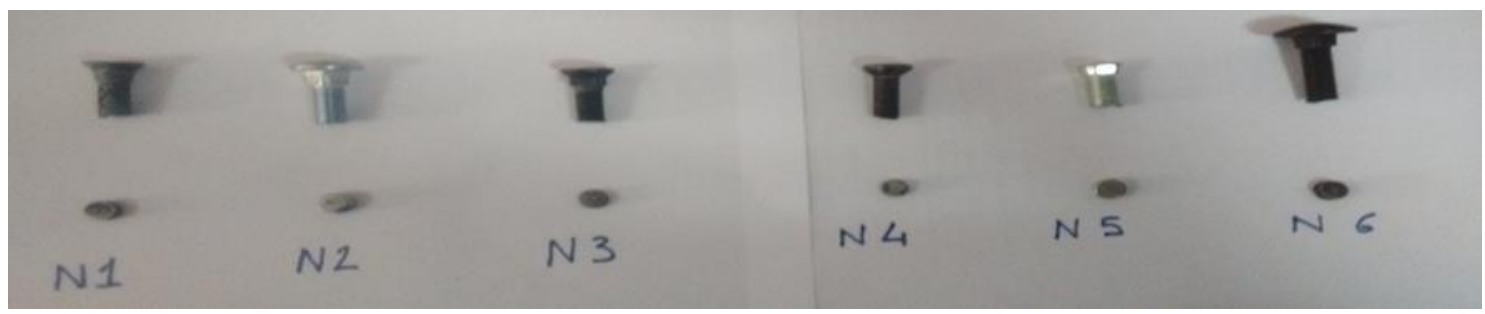

Figure 2: Bolt samples

\subsection{Sample Grinding and Polishing Machine}

Before examining the specimens from the plow endmills, the surfaces must be precisely trimmed. For this purpose, firstly, polishing with different abrasive paper was done and lastly surface polishing process was done on the cloth. The device is shown in Figure 3. 


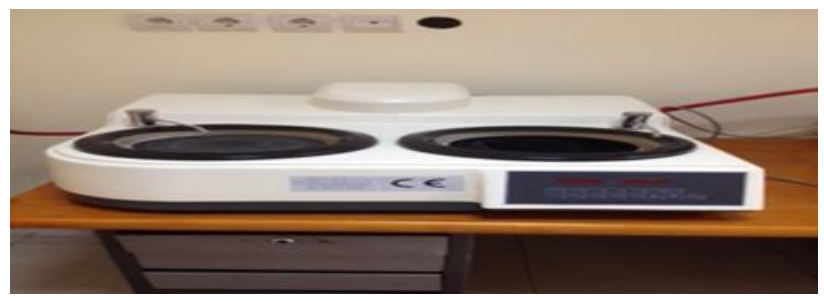

Figure 3: Sample grinding and polishing machine

\subsection{Computer Controlled TRD Wear Abrasion Tester}

The wear tester is set at the desired speed range $(\mathrm{d} / \mathrm{min})$ and load $(\mathrm{N})$ values. The work was carried out at $763 \mathrm{~d} / \mathrm{min}$ and $20 \mathrm{~N}$ loads. The coefficient of friction at the end of wear is visible on the computer screen. The device is shown in Figure 4.

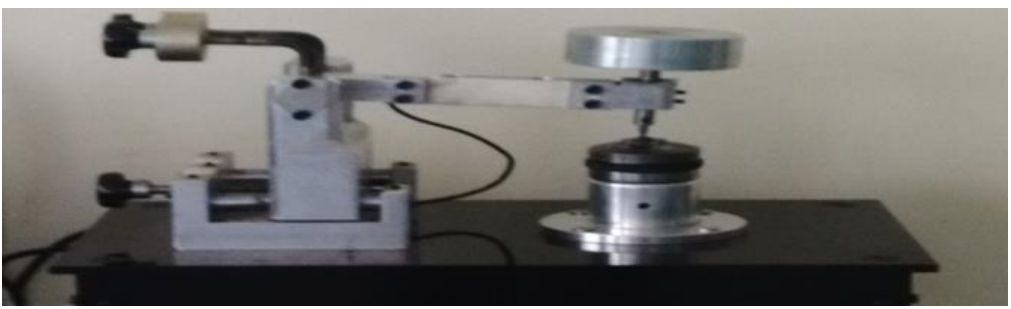

Figure 4: Wear device

\subsection{Precision Balance}

In our work, we used a precision scale with a precision of $0.001 \mathrm{gr}$ to determine the loss of weight in the sample, at the end of wear. The device is shown in Figure 5.

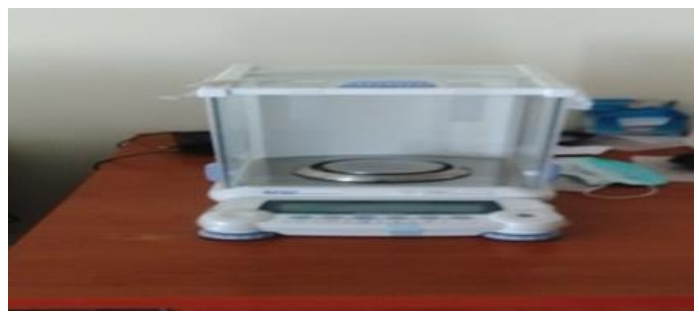

Figure 5: Precision balance

\subsection{Manual Metal Hardness Measurement Device}

Brinell (HB) hardness was determined using a manual metal hardness tester before the friction coefficients of the samples that were determined. The device is shown in Figure 6.

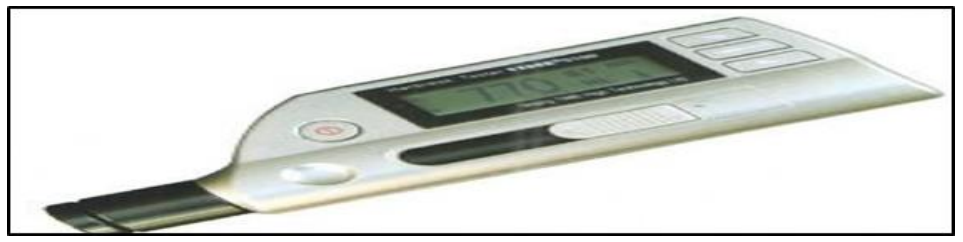

Figure 6: Manual metal hardness tester 


\section{Results and Discussion}

\subsection{Determination of Friction Coefficients of Bolts}

6 different bolt samples were fitted separately to the TRD wear device and friction coefficients were found. A load of $20 \mathrm{~N}$ (Newton) was applied when the friction coefficients were determined.

First, the friction coefficients for samples $1,2,3,4,5$, and 6 were determined. The result values are shown in Figures 7, 8, 9, 10, 11 and 12.

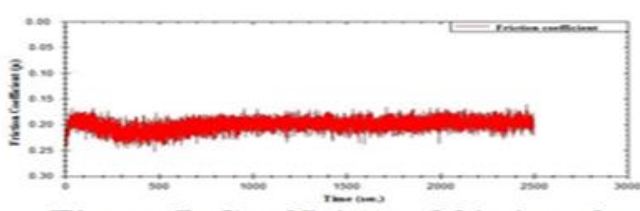

Figure 7. Coefficient of friction for sample 1

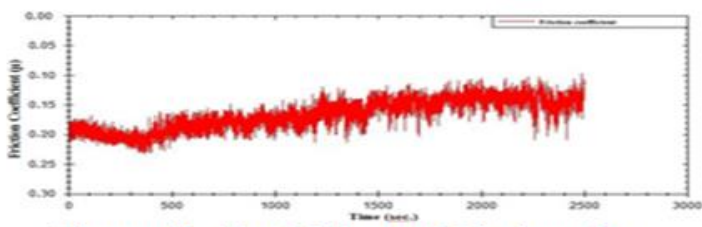

Figure 9. Coefficient of friction for sample 3

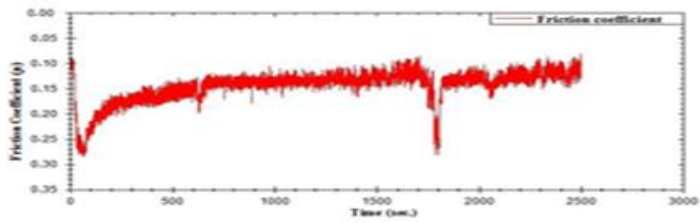

Figure 11. Coefficient of friction for sample 5

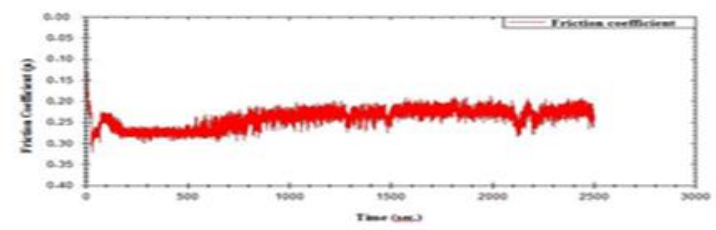

Figure 8. Coefficient of friction for sample 2

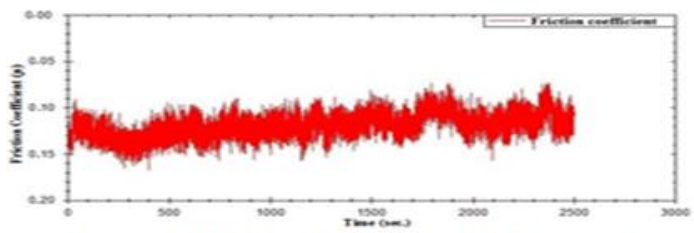

Figure 10. Coefficient of friction for sample 4

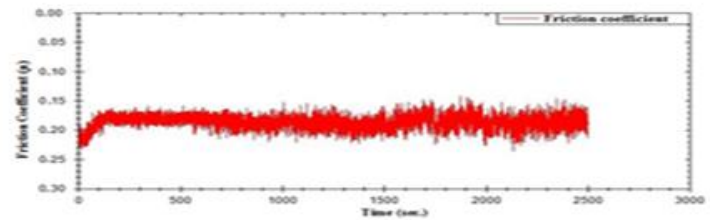

Figure 12. Coefficient of friction for sample 6

The following graph is obtained by calculating the average values of the friction coefficient values obtained from the 6 bolt samples above. The chart is shown in Figure 13.

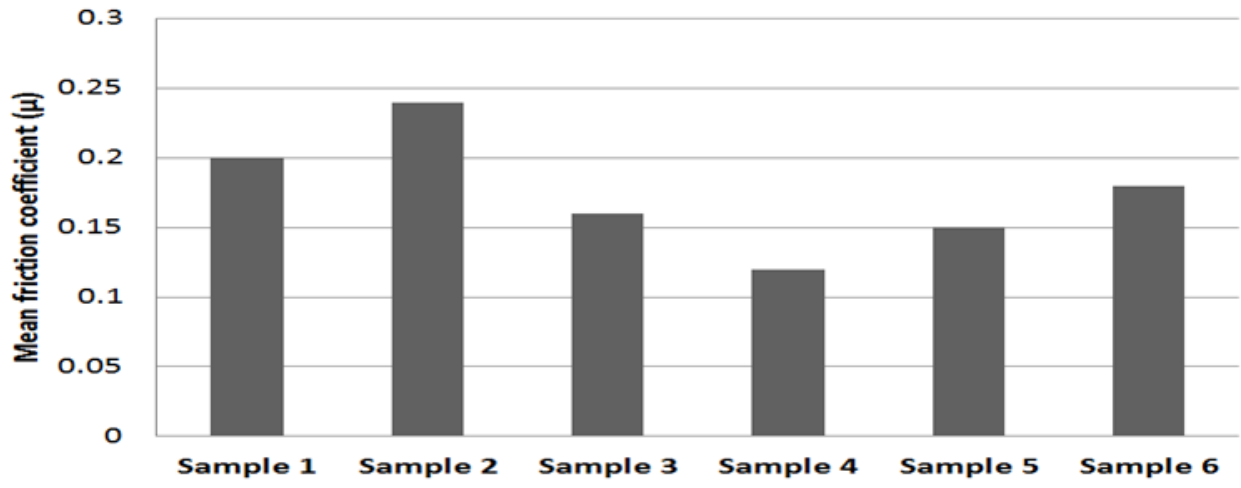

Figure 13: Mean friction coefficient 
The friction coefficient is a unitless value known as the ratio of the force holding the two surfaces together to the friction force. This value varies depending on the compression torque applied, the nut and bolt-on-bolt compression. The change in the friction coefficient can lead to deformation of the bolt or nut, loosening the connection. Therefore, different clamping forces for different connections, applications that will prevent the opening of the connection, material type, etc. should be applied.

It is seen in Figure 13 that the friction coefficient is the largest at 0.24 and the sample 2. The others, Samp. 1 (0.20), Samp. 6 (0.18), Samp. 3 (0.16), Samp. 5 (0.15), Samp. 4 (0.12), Samp. respectively.

\subsection{Percent Wear Rates and Hardness Values in Bolts}

Each sample was tested in a TRD wear device under load of 2500 seconds to $20 \mathrm{~N}$. At the end of the treatment, the weight $(\mathrm{g})$ and the initial weight $(\mathrm{g})$ are taken into account and calculated using the following $\%$ wear rate formula.

Wear Rate $(\%)=\frac{\text { First Weight }(\mathrm{g})-\text { Final Weight }(\mathrm{g})}{\text { First Weight }(\mathrm{g})} * \mathbf{1 0 0}$

The wear ratios obtained from the samples are given in Table 1.

Table 1: Wear rates $(\%)$

\begin{tabular}{|l|l|l|l|}
\hline Sample Numbers & First Weight (g) & Final Weight (g) & Wear Rate (\%) \\
\hline 1 & 2.268 & 2.267 & 0.045 \\
\hline 2 & 3.436 & 3.434 & 0.060 \\
\hline 3 & 4.091 & 4.090 & 0.024 \\
\hline 4 & 4.229 & 4.228 & 0.023 \\
\hline 5 & 4.085 & 4.084 & 0.024 \\
\hline 6 & 2.468 & 2.467 & 0.040 \\
\hline
\end{tabular}

Figure 14 is obtained using the wear rate values in Table 1.

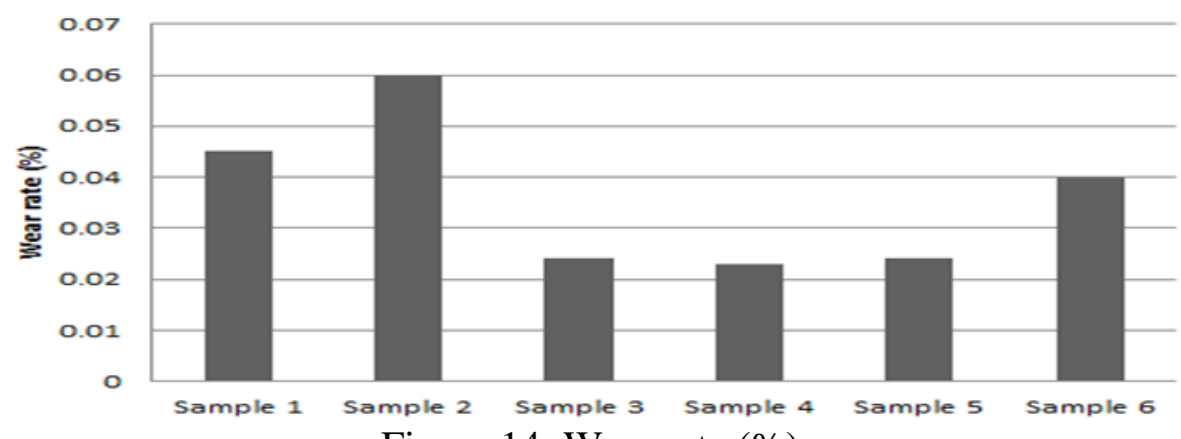

Figure 14: Wear rate $(\%)$

When the wear rate graph shows that the maximum material loss is sample 2 samp. 1, samp. 6 samp. 3, samp. 5 and samp. 4 It can be seen. 
Hardness measurements in the samples were made in brinell (HB). Averages of the results obtained from 5 different points on the sample were taken. The results of material hardness measurement are given in Table 2.

Table 2: Sample hardness values (HB)

\begin{tabular}{|l|c|c|c|c|c|c|}
\hline & \multicolumn{6}{|c|}{ Hardness value (HB) } \\
\hline & $\mathbf{1}$ & $\mathbf{2}$ & $\mathbf{3}$ & $\mathbf{4}$ & $\mathbf{5}$ & Mean hardness value \\
\hline Sample 1 & 116 & 125 & 122 & 124 & 120 & 121 \\
\hline Sample 2 & 100 & 150 & 156 & 138 & 141 & 137 \\
\hline Sample 3 & 116 & 100 & 110 & 98 & 104 & 105 \\
\hline Sample 4 & 102 & 94 & 110 & 95 & 100 & 100 \\
\hline Sample 5 & 100 & 92 & 105 & 110 & 100 & 101 \\
\hline Sample 6 & 105 & 115 & 105 & 115 & 114 & 111 \\
\hline
\end{tabular}

Table 2 shows that the hardest specimen is 2 and the least hard specimen is 4 .

\subsection{Comparison of Friction Coefficient, Wear Rate and Hardness}

In order to determine the relationship between the pre-determined friction coefficients, wear rate and hardness values, we have created Figure 15 below.

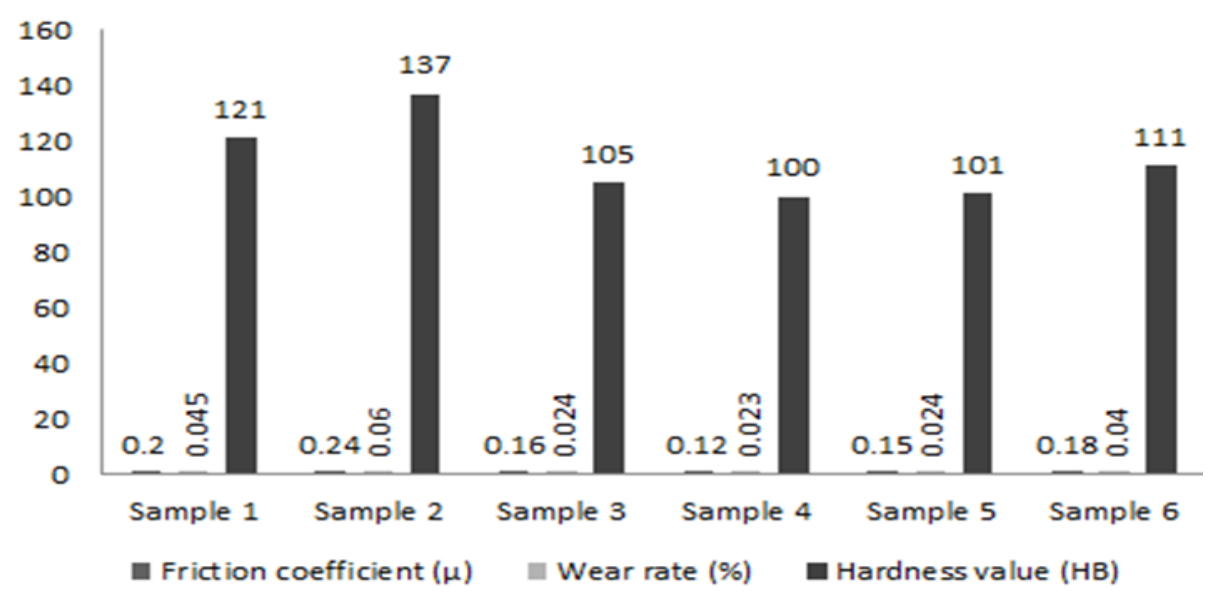

Figure 15: Comparison chart

There is generally a right ratio between the material hardness and friction coefficient. Friction is greater in hard materials and the amount of wear increases accordingly. In Table 3 below, friction coefficients are given for some materials.

Table 3: Friction coefficients of some materials

\begin{tabular}{|l|l|l|}
\hline & $\boldsymbol{\mu}_{\mathbf{s}}$ & $\boldsymbol{\mu}_{\mathbf{k}}$ \\
\hline Steel on steel & 0.74 & 0.57 \\
\hline Aluminum on steel & 0.61 & 0.47 \\
\hline Copper on steel & 0.53 & 0.36 \\
\hline
\end{tabular}




\begin{tabular}{|l|l|l|}
\hline Rubber on concrete & 1 & 0.8 \\
\hline Wood on board & $0.25-0.5$ & 0.2 \\
\hline Glass on glass & 0.94 & 0.4 \\
\hline Polished wood on wet snow & 0.14 & 0.1 \\
\hline Polished board on dry snow & - & 0.04 \\
\hline Metal on metal (oiled) & 0.15 & 0.06 \\
\hline Ice on ice & 0.1 & 0.03 \\
\hline Teflon on Teflon & 0.04 & 0.04 \\
\hline Human joint connections & 0.01 & 0.003 \\
\hline
\end{tabular}

Table 3 shows a decrease in friction coefficients, especially on steel, and copper on steel, due to reduced material hardness. A similar situation emerged in the study. The most abrasive and friction coefficient for Sample 2, which is the hardest. This was followed by Sample 1 and Sample 6, respectively. For Sample 3, Sample 5 and Sample 4, the hardness values were very close to each other and little difference was observed.

There are a variety of factors affecting wear on bolt and nut connections. We can classify them as main material, counter material, intermediate material, load and movement. For example, the coefficient of friction is normally classified as static and kinetic. The static coefficient of friction is still higher and known as the static friction coefficient. The coefficient of friction in motion is lower and known as the kinetic friction coefficient. For these reasons, production must be carried out on account of certain considerations in the design of connections. In this way, many direct and indirect failures due to the deterioration of the bolt connections during operation will be avoided. Regarding this:

- Selection of bolt material suitable for bonding materials

- Compression torque is made in the proper setting

- Taking measures to reduce friction

- Correct calculation of stresses and loads acting on bolts during operation

- Methods that prevent opening the connection during operation

- Applications such as selection of materials suitable for standards can be made.

\section{Conclusions}

Bolts from removable connection elements, which we often encounter in daily and even in many places, are often carried out without any scientific approach. Although this approach does not cause any problems in simple places where the precaution is not high, it is especially necessary to observe certain criteria when used as a machine tool. We normally classify machine elements as critical and non-critical as a design approach. Non-critical parts do not have any load on them, which are easy to produce and easy to obtain, inexpensive, and do not affect the system very much if it gets damaged. The opposite of these criteria is defined as the critical part. Critical parts are usually made as detachable connection. In the detachable connection methods, the most screwed connections are used. 
Especially in the agricultural machinery, the parts which are in the soil are exposed to the most abrasion and breakage. For this reason, these parts are made of bolted connections. One of these pieces is plow end iron. Bolts must withstand the longest lasting effect, not reducing work efficiency during operation. In addition, when an extreme strain occurs, the tip must be broken before the tip breaks to protect it. Because of this and many other reasons, work on bolted connections has been carried out in order to make a proper connection and to open the door for new scientific developments.

In our study, 6 different plow tip drill bolts have been studied in terms of certain criteria. As a result, it has been determined that the abrasion rate and the coefficient of friction increase due to hardness in hard materials. Studies should be undertaken to design more appropriate bolts in these and similar studies, or to reduce the adverse effects of existing bolted connections.

\section{References}

[1] Spakale PR, Tiwari G, Sharma AK. Influence of surface hardening processes on wear Characteristics of soil working tools-a review. International Journal of Engineering Science \& Technologies Emerging Technologies 2016; 8:191-201.

[2] Kup F, Aslantas M. Comparison kultivator duck-foot shares in respect of hardness and wear rates. Harran Journal and Agricultural and Food Science 2018; 22(1): 126-136.

[3] Gupta AK, Jesudas DM, Das PK et al. Performance evaluation of different types of steel for duck foot sweep application. Biosystems Enginnering 2004; 88(1):63-74.

[4] Cakmak B. Effects of different heat treatments on wearing resistance of disc harrow discs. Ege Journal of Agricultural Resarch 2001. 38(1):79-84,

[5] Korucu T, Arslan S. The effect of wear rate of cultivator shares and operating speed on draught force requirements. KSU Journal of Science and Engineering 2008. 11(1):82-88,

[6] Anappa A.R, Basavarajappa S. Some studies on three body abrasive wear behavior of hardfaced and normal plough tool material using Taguchi method. International Journal of Surface Science and Engineering 2013. 7(1):14-26,

[7] Mohsenin N, Womochel H. L. "Wear tests of plough share materials. Journal of Agricultural Eng. 2005. 25:816-820,

[8] Kinit U. Experimental investigation static strength values of 30mnb4 bolt material by different heat treatment. Istanbul Technical University, Graduate School of Science Engineering and Technology, Master Thesis 2013. 97s Istanbul.

[9] Kuçukatalay GD. The effects of distance between fastener holes and hole diameter on tensile strenght of bolt and nut joints. Baskent University Institute of Science and Engineering, Master Thesis 2010. 75s Ankara.

[10] Cavdar K, Bilal H, Ince U. Development a methodology on the self-loosening of threaded fasteners. Otekon'14 7. Automotive Technologies Congress 26-27 May 2014. Bursa

\footnotetext{
*Corresponding author.

E-mail address: ferkup63@ harran.edu.tr
} 